The proceedings were opened by the Duke of Edinburgh who struck a political note by welcoming the recent government reorganization which created the Department of the Environment. He also advocated yet more administrative coordination, but noted that the real bar to environmental progress is likely to be the allocation and spending of the necessary funds.

Urbanization and industry dominated the first day's proceedings, and so perhaps it was to be expected that population and economic growth should have had their usual airing. The naturalist Mr Richard Fitter propounded a basic equation of conservation: $q=r / p^{2}$, where $q$ is the quality of life, $r$ represents available resources and $p$ is the population. If $r$ cannot be increased, Mr Fitter said, then to maintain $q$, the only thing to do is to keep $p$ steady. He was supported by a call for the conference to ask the government to provide everybody in Britain with free contraceptives. There was applause for a demand for a national population policy and an end to the striving for economie growth at all costs.

The industrialists, not surprisingly, leapt to their own defence, pointing out, in the person of $\mathrm{Mr} \mathrm{A}$. E. Higginson, of the Institute of Public Cleansing, that in the manufacturing industries it is often cheaper to use fresh raw materials than to recycle wastes. In a very competitive world, he said, to the scorn of many a conservationist, the price and quality of goods are paramount. The industrialists were, of course, also quick to point out how much they have done for conservation. The Sand and Gravel Association, for example, is to give an award for the best example of restored sand and gravel workings.

But an applause meter would have shown that many of the delegates were not impressed by such industrial largesse. For once, the National Union of Students received a wide measure of support. Mr G. Searle, a member of the NUS executive, called for recycling of wastes and a firm hand on companies seeking to build factories on sites of natural beauty. Mr Searle also lamented the lack of debate in the proceedings, but doubtless it is difficult to bring new arguments to bear at this stage in the environmental crisis. It is time for action now.

\section{FOOT AND MOUTH Mystery Outbreak at Pirbright}

SIX cattle in a special holding pen outside the experimental compound, but within the security perimeter, of the Animal Virus Research Institute at Pirbright, Surrey, recently developed symptoms of foot and mouth disease. Within a few hours three more animals had contracted the infection, and shortly afterwards the entire group of eighteen animals had to be destroyed. There has been considerable speculation about the cause of the outbreak, but the source of infection is still not known, and, apart from long term projects whose progress could not be jeopardized, research has been suspended while investigations are in progress.

There seem to be three ways in which the outbreak could have arisen. First, the virus may have been brought in from outside the institute, but this frightening possibility is fortunately remote, because no other outbreaks have been reported in the area. Alternatively, the disease may have been carried physically from the experimental compound to the holding pens; again this seems unlikely because the Pirbright administration are fully aware of this danger and their security precautions are rigorous. Finally, a few virus particles may have escaped through a temporary breakdown in the filters which clean the outgoing air from the experimental compound. These filters were checked and found to be working perfectly as soon as the outbreak was confirmed, but it is well known that no biological filter can be more than 99.9 per cent efficient, and this seems the most likely source of the infection.

The chance of such an escape is a danger that all disease research stations live with, but in ten years there have been only two such incidents at Pirbright and both have been confined within the perimeter of the institute.

The role that may be played by the wind in spreading viral infections is still a matter of contention (see, for example, Nature, 22\%, 860; 1970) and so the possibility that viral particles may be able to defeat the highly sophisticated filters developed at Pirbright is a cause for concern. But the risk to livestock on the farms surrounding Pirbright and elsewhere seems minimal. Dr J. B. Brooksby, director of the institute, pointed out last week that for 35 years the institute has carried out a full research programme, using the distinctive African variety of virus, without air filtration and with no greater incidence of infection than in the rest of the country.

\section{PESTICIDES}

\section{More Research Required}

THE overwhelming impression left by the third report of the Research Committee on Toxic Chemicals (Agricultural Research Council, available from HMSO, $5 s$ ) is that a great deal more information will have to be collated before conclusions can be reached and the right decisions taken. The report has comforting things to say about the level of DDT in human fatty tissue but about little else. Six appendices provide a host of factual information but otherwise serve only to illustrate how difficult it is to make specific recommendations on insufficient data.

The committee's first report in 1964 placed special emphasis on the need for more research into the effects of pesticides in fresh water, and almost one third of the present report is concerned with this topic. Fresh and rain water in Britain contains small but not insignificant amounts of the chief persistent organochloride pesticides, DDT, lindane and dieldrin. The estimated amount lies between 3 and 30 parts in $10^{11}$. The report concludes that such a level is within the margins of safety, but precariously so. Experiments have indicated that if the concentration of any organochloride residue should rise to more than 1 part in $10^{10}$, freshwater fish and other aquatic organisms would be at considerable risk.

The report suggests three methods of approaching the problem. First, a coordinated system of surveillance should be established in collaboration with the River Authorities and the Natural Environment Research Council to plot the pattern of pesticide distribution in rivers, lakes and reservoirs. Second, the ways in which pesticides may affect organisms against which they are not directed must be examined in much greater depth. The final recommendation deals with the destruction of pesticides. It is difficult to destroy pesticides once they 